\title{
SMST Entrepreneurial Workshop, May 2020
}

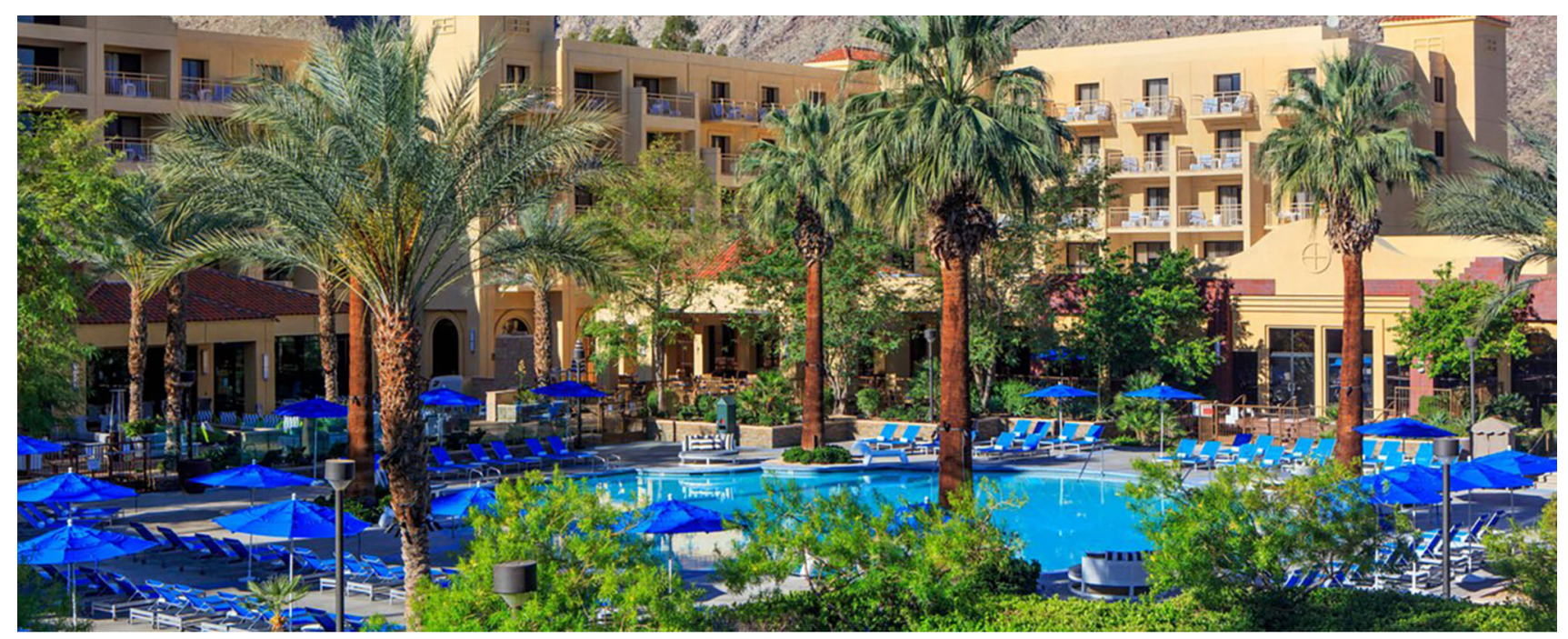

\section{Renaissance Palm Springs Hotel}

The International Conference on Shape Memory and Superelastic Technologies (SMST) Entrepreneurial Workshop will be held on May 4-5, 2020 at the Palm Springs Convention Center/Renaissance in Palm Springs, California. This year, the event is co-located with AeroMat 2020 which runs from May 4-6.

This 1.5-day workshop, co-chaired by Tad Calkins of The Boeing Company and Jeremy Schaffer of Fort Wayne Metals, will provide education toward startup success from technology and business experts for Shape Memory Alloy entrepreneurs across all fields, existing and emerging. These short talks and panel discussions are designed to recognize, encourage, and support the SMA ecosystem. The workshop will also feature networking events and a pitch session with live expert feedback to engage new and experienced SMA entrepreneurs.

The Palm Springs Convention Center is located with the Renaissance Palm Springs Hotel located in downtown Palm Springs, California bordered by the San Jacinto Mountains in the Coachella Valley.

For more information and to register for the SMST Entrepreneurial Workshop, please visit https://www. asminternational.org/web/smst-event/home. 